\title{
$\$$ Research Square

\section{"We do not know how to screen and provide treatment": A qualitative study of barriers and enablers of implementing perinatal depression health services in Ethiopia}

Abel Dadi ( $\sim$ Fekten@yahoo.com )

University Of Gondar

Emma Miller

Flinders University

Telake Azale

University Of Gondar

Lillian Mwanri

Flinders University

\section{Research Article}

Keywords: perinatal depression, Health system, Ethiopia

Posted Date: December 21st, 2020

DOl: https://doi.org/10.21203/rs.3.rs-125401/v1

License: (c) (i) This work is licensed under a Creative Commons Attribution 4.0 International License.

Read Full License 


\section{Abstract}

Background: Qualitative studies evaluating maternal mental health services are lacking in Ethiopia, and the available evidence targets severe mental illnesses in the general population. We conducted a qualitative study to explore barriers to, enablers of, or opportunities for perinatal depression health services implementations in Ethiopia.

Methods: We conducted a total of 13 face to face interviews with mental and maternal health service administrators from different levels of the Ethiopian healthcare system. We interviewed in Amharic (a local language), transcribed and translated into English, and imported into NVivo. We analysed the translated interviews inductively using thematic framework analysis.

Results: The study identified: (i) health administrators' low literacy about perinatal depression as individual level barriers; (ii) community low awareness, health-seeking behaviours and cultural norms about perinatal depression as socio-cultural level barriers; (iii) lack of government capacity, readiness, and priority of screening and managing perinatal depression as organisational level barriers; and (iv) lack of mental health policy, strategies, and healthcare systems as structural level barriers of perinatal mental health implementation in Ethiopia. The introduction of the new Mental Health Gap Action Programme (mhGap), health professionals' commitment, and simplicity of screening programs were identified enablers of, or opportunities for, perinatal mental health service implementation.

Conclusions: This qualitative inquiry identified important barriers and potential opportunities that could be used to address perinatal depression in Ethiopia. Building the capacity of policy makers and planners, strengthening the mental healthcare system and governance should be a priority issue for an effective integration of maternal mental health care with the routine maternal health services in Ethiopia.

\section{Background}

Depression is one of the most common complications of the perinatal period, both in high (1) and lowincome countries (2). In Ethiopia, the prevalence of antenatal depression ranges from $11 \%$ to $31 \%$ (3), while the prevalence of postnatal depression ranges from 12 to $33 \%(4,5)$. Untreated depression during pregnancy has been reported to increase the risk of obstetric complications $(6)$, poor foetal growth $(7,8)$, and adverse birth outcomes $(1,2)$. Similarly, untreated postnatal depression is reported to increase the risk of adverse infant health outcomes $(9,10)$ and their future educational achievement $(11)$. The negative impacts of perinatal depression on family and social disruption have been reported in different studies $(4,12,13)$.

Despite efforts to mitigate the substantial burden of perinatal depression in developed countries, much remains to be done in low-and middle-income countries (14-18). In terms of access, mental health services in Ethiopia are numerically limited, geographically inaccessible, and hospital-based (19). The treatment gap for postnatal depression is near to $95 \%$ (20), and, while unknown at this stage, it is expected to be similar for antenatal depression. Barriers to poor treatment are multifactorial and could be 
associated with personal behaviour $(21,22)$, the severity of the disorder $(20)$, social norms $(23)$, and the lack of effective mental health care systems (24). There is a global initiative to reach women with mental disorders by integrating mental and maternal health services $(25,26)$. However, situational analysis in five low- and middle-income countries showed a limited capacity of the health systems regarding feasible detection and treatment strategies (27).

In order to provide the right maternal mental health care where and when it is needed, it is critical to integrate maternal mental health services into the existing health system (28). Appropriate service delivery, human resources for health, information, health technologies, budget, and governance structure are fundamental to building an effective health system (29). Two programs have been running in Ethiopia to scale up maternal mental health services: (i) A Program for Improving Mental Health care (PRIME), which aims to generate evidence on the implementation and scale-up of mental health service integration (30); and (ii) The Emerging mental health system in low-and middle-income countries (Emerald), which aims to improve mental health outcomes by generating capacity and evidence (31). The Emerald program focuses on identifying health system barriers and developing solutions to improve the effective delivery of mental health services. Although there have been some quantitative studies focusing on severe mental illnesses in the general population in Ethiopia $(19,32,33)$, there is a lack of qualitative studies that have investigated maternal mental health system and identified barriers to effective care of antenatal depression. In depth information provided by qualitative approaches would help to identify gaps in policy, program, and health system that need to be addressed for successful integration of mental health services into routine maternal health services. This qualitative study explored health administrators' and community perspectives of the health system's response, barriers and enablers for effective perinatal depression care service delivery in Ethiopia.

\section{Methodology}

\section{Theoretical framework}

We used Smith's et al (34) Multilevel Conceptual Framework for barriers hindering maternal mental health services to aid the analysis, synthesis and summarizing of the study findings. The model posits that mental health service delivery is affected by individual, organizational, sociocultural, and structural level barriers. Individual level barriers include factors such as knowledge, attitude, and behaviour of the community, health professionals, and health administrators working at different levels. The sociocultural related barriers include language, cultural values of the community, and women's perceptions of perinatal depression. The organizational-level barriers include the capacity and readiness of the health facilities or organizations to provide maternal mental health services. This might have elements such as lack of resources (trained workforce, money), time (patient load), space (lack of adequate offices), lack of clarity in role and responsibilities, lack of working manuals, screening tools, treatment guidelines, and protocols. Finally, structural level barriers include lack of policy, program, and strategies, low attention and initiation by the government, and lack of transparent system and structure.

\section{Study Setting And Recruitment Of Study Population}


Ethiopia, a country located in the Eastern part (horn) of Africa, is administratively subdivided into nine regional states and two central cities (35). The Ethiopian Federal Ministry of Health (FMOH) is mandated to formulate national policies, plans and programs for the health sector. Under $\mathrm{FMOH}$, all regions have health bureaus', zonal health offices, hospitals, and health centres. Health structures under FMOH are centrally controlled, and all plans and programs cascade to the lower level of the health system. In the Ethiopian health care system, mental health service delivery involves the two wings of the healthcare system structure, health bureaus and health facilities. In health facilities, perinatal women can directly visit the psychiatry clinics for mental health services. Alternatively, they can visit the maternal and child health $(\mathrm{MCH})$ clinic for routine follow up where they might be screened for mental health problems. Similarly, in the health bureaus, the mental health care team and $\mathrm{MCH}$ care team are involved in perinatal mental health service delivery.

We purposely sampled health administrators from different levels of the Ethiopian healthcare system focusing in Amhara Regional State $(36,37)$, to explore their perspectives and gain an in-depth understanding of perinatal depression care service delivery in the nation. We interviewed a total of 13 participants who were leaders at different levels in mental health or maternal health services. The number of participants interviewed was determined by information saturation $(36,38)$.

\section{Data Collection}

We used a pre-tested semi-structured interview guide prepared in English and translated to Amharic (local language of the data collection area) to collect the data. The interview guide was developed based on literature related to the main research question. In addition, we used probes, cues and prompts that directed the interviewees to focus on areas relevant to the research topic to enable collection of relevant and in-depth data (39). The principal investigator (AFD) interviewed each participant face-to-face in their private offices (which were quiet, secure and comfortable) to maintain the quality of the recordings and facilitate open discussion (40-42). The interviews were audio-recorded and took 15-35 minutes, with a summary of important points made at the end to make sure that the responses were correct and fully documented.

\section{Ethical Consideration}

The research was approved both by the Social and Behavioural Research Ethics Committee of the Flinders University, Australia (reference number 7959, 2018) and the Institutional Review Board of the University of Gondar (reference number O/V/P/RCS/05/1601, 2018). Study participants were informed about the purpose, objectives, and their right to decline participation or withdraw from participation at any time. Informed consent was obtained from each participant. Privacy and confidentiality were maintained throughout the study.

\section{Data analysis}


We transcribed and translated the audio-recorded interviews verbatim, imported the data into NVivo software (43) and applied a thematic framework analysis (44). The analysis involved the following steps: data familiarisation, coding, identification of a thematic framework, indexing, charting and data interpretation. Data familiarization occurred through the processes of transcribing and repeated listening to audio tapes, which helped to systematically identify initial ideas for coding (40). After coding the first two transcripts, a thematic framework was developed by the research team for indexing the remaining transcripts. Indexing in NVivo is accomplished by adding concepts and ideas from the transcripts to the related codes and categorise created in the identified thematic framework. We used both inductive and deductive approaches to account for categories that were known a priori and those that originated from the data (45). A framework matrix was developed that clearly outlined the themes, sub-themes, and their description with their respective files and references. Finally, the emerged themes, sub-themes with their clear descriptors were organized, presented and interpreted for meaning. Each theme and sub-themes with their central meaning were described and presented supported by quotes obtained from the study participants (45-48).

\section{Results}

\section{Characteristics of the study participants}

Socio-demographic characteristic of the participants are described in table 7. A total of 13 participants were involved in this study, nine of whom were male (69\%). The median age of participants was 34 years (range 26-55 years) and the median work experience was 11 years (range 4-35 years). Participants' professional backgrounds were varied, with midwifery (6) and public health (4) being the two largest groups. 
Table 1

Characteristics of the interview participants involved in a qualitative study, Gondar Town, Ethiopia $(\mathrm{N}=13)$.

\begin{tabular}{|ll|}
\hline Participant characteristics & Participants $(\mathbf{N}=13)$ \\
\hline Median age (range) & $34(26,55)$ \\
\hline Sex & 9 \\
\hline Male & 4 \\
\hline Female & $11(4,35)$ \\
\hline Median work experience in the health system (range) & \\
\hline Profession & 6 \\
\hline Midwifery & 2 \\
\hline Psychiatrists & 1 \\
\hline Psychologist & 4 \\
\hline Master of Public Health & \\
\hline Place of work & 6 \\
\hline Health offices & 4 \\
\hline Hospitals & 3 \\
\hline Health centres & \\
\hline
\end{tabular}

Three main themes, with 13 sub-themes, emerged as barriers to, enablers of, or opportunities for perinatal depression health services implementations in Ethiopia: (i) health administrators' and community knowledge about perinatal depression, (ii) fragmentation of health system, and (iii) enablers and opportunities. These are described in detail in Table 2. 
Table 2

Summary of barriers to perinatal depression health services implementations in Ethiopia, $2018(N=13)$

Themes

Health administrators' and community knowledge or awareness about perinatal depression
Sub-themes

1. Conceptualising perinatal depression

2. Risk factors

3. Signs and symptoms

4. Onset of symptoms and screening

5. Consequences

6. Interventions

7. Community awareness and culture

Fragmented health system

8. Government capacity, readiness, and prioritisation of perinatal depression

9. Perinatal mental health policy and strategy

10. Lack of perinatal mental healthcare system

Enablers and opportunities
11. Introduction of the new mhGap action program

12. Health professionals' commitment

13. Simplicity of screening program

\section{Health administrators' and community (public) awareness about perinatal depression}

Seven key sub-themes emerged from the first theme, explaining the roles that health administrators and community mental health awareness and cultural issues played as barriers to implementing perinatal depression health services in Ethiopia.

\section{Conceptualising perinatal depression}

Proper conceptualisation of perinatal mental health or depression by health administrators is a crucial step in order for them to develop appropriate strategies to address the disorder. Some administrators related the concept of perinatal depression to the WHO definition, which proposes health as a state of complete physical, mental and social well-being and not merely the absence of disease or infirmity (49). Thus, the concept of health should account for mental health, which is important in keeping the psychological, spiritual, and emotional component of human health. One health administrator interviewed said: 
A mother is said to be healthy as defined by the WHO: if she can use her mind properly, if she can resist for any source of stressors, if she is fruitful in any work or activity, and if she can manage or administer her family properly. In line to the WHO definition, health is not merely the absence of disease but should also include mental wellbeing. (Male, aged 32 years)

Other participants used a range of indicators to define maternal mental health. According to their perceptions, if the mother is free from depression, she would: (i) adhere to perinatal follow-up and usual activities; (ii) overcome challenges (e.g. adjust or withstand life stressors or events related to parenthood); (iii) be confident about herself and her pregnancy (e.g. she has positive thoughts, she is happy and feels healthy during pregnancy or after birth); (iv) have good social and personal interactions. These assertions are seen in the following quote.

So, if the mother is mentally healthy, she should be socially, physically, and mentally healthy. In the other way, if she can perform her usual activity, comes for follow-up services, and if she can comprehend what clinicians have said about her health, we can say she is mentally healthy. (Female, aged 50 years)

Nearly half of participants stated that they did not know about perinatal depression, or they were not sure about it. Other respondents argued that there was no literature or documents written about perinatal depression and the available working guidelines by the government did not mention perinatal depression. Some respondents did not distinguish between to perinatal and post-natal depression. One of the interviewees indicated their lack of knowledge about perinatal depression:

I do not have any idea about perinatal depression though I am a non-communicable disease officer. We are using the new non-communicable disease guideline developed by the Federal Ministry of Health and perinatal depression is not included in the guideline. (Male, aged 41 years)

\section{Health administrators' knowledge about risk factors for perinatal depression}

Health administrators' knowledge of risk factors for or causes of perinatal depression is important to enhance their active involvement in designing interventions that would help in prevention and management of perinatal depression. There was a range of understandings expressed about by participants, some of whom indicated relatively limited awareness about risk factors for perinatal depression.

A number of respondents proposed that individual characteristics such as female sex, younger age or older age, and personal misbehaviours such as substance use, alcoholism, drug and smoking are risk factors for depression. It was noted from the interviews that these participants did not have awareness or knowledge about perinatal depression specifically as they were focused on mentioning risk factors similar to those for depression in the general population. One of the participants mentioned,

Those who are addicted to alcohol, chat, cigarettes are more depressed. After they already immersed into it, and when they could not get these substances, they would develop depression symptoms. (Male, aged 52 years). 
The reason for this (depression) might not be clear but the epidemiology showed that depression is higher in females than males. This might be because women are not emotionally strong than males. (Male, aged 29 years)

Fewer than a quarter of participants agreed that the perinatal period by itself could be a risk factor for depression. They proposed that stress associated with the physiological and hormonal changes happening during pregnancy and the postnatal period could lead to depression. Furthermore, women might start to develop psychological stress in the early stage of pregnancy, related to body image changes impending childcare responsibilities and/or other family issues. To demonstrate this, participants said:

Depression could occur during pregnancy or after birth because of some hormonal imbalances and the women would benefit from psychosocial support given by partner or any family members. (Male, aged 26 years).

...especially pregnant women, if in their early stage of pregnancy, when they feel different or start thinking about their pregnancy and the new environment after birth, they might be exposed to depression. (Male, aged 29 years)

Most participants, however, argued that the perinatal period by itself was not a risk factor for depression except for women facing additional risk factors. The proposed factors included: early age or first-time pregnancy, cultural beliefs, economic concerns, lifestyle risks such as substance misuse, poor health status during the perinatal period, sleep problems, and/or psychosocial problems related to marital relations, limited partner and social support, or unwanted or unplanned pregnancy. The following quotes illustrate the above understandings:

Sometimes it (depression) might happen to women when they are in low economic condition or financial struggle. Mostly, pregnant mothers who were pregnant for unwanted or unintended pregnancy are also stressed. If there are young to their age and very difficult for them to handle the pregnancy or they have other duties, they might start to feel depressed. However, I do not believe that pregnancy by itself is a risk factor for depression. (Female, aged 55 years).

... as a culture, when everybody comes to visit the mother, coffee should be served, and such gathering having repeated coffee ceremony might affect their (women) sleep frequency and quality as it is known that caffeine interferes with sleep. Taking care of their kids for long time in the night and their responsibility of leading family put these women not to have adequate sleep leading them to stress and depression. (Male, aged 29 years)

Further cultural risk factors for depression identified by participants included the lack of a person accompanying the mother during delivery. It was suggested that unaccompanied women immediately after delivery might be fearful or even begin to develop psychotic thoughts. It was proposed that lack of 
partner or family support may result in feelings of loneliness, worthlessness or feeling ignored. As one participant said:

..., for example, there is a saying after delivery called, "they leave me alone" or "she/he left me alone". Psychosis or post psychosis might occur like this. Isn't it? They might be tensioned for unknown reasons; can't we say this a peripheral psychosis? (Female, aged 55 years).

While psychosocial, genetic, and biological changes related to pregnancy and childbirth were identified as risk factors, some participants stated their belief that the cause of perinatal depression is not well known. One mentioned that the disorder is mostly suspected when the mother starts 'accidentally hating' her baby. These participants proposed that specific causes of perinatal depression are still subject to debate in scientific literature.

The cause of depression could be related to delivery, pregnancy, genetics or natural, but this is one of the controversial issues for debate. (Male, aged 32 years).

\section{Health administrators' awareness about signs and symptoms of perinatal depression}

Knowledge about signs and symptoms of perinatal depression is important for early identification and intervention. This sub-theme reflects health administrators' understanding of the signs and symptoms of perinatal depression. Most participants described signs and symptoms of perinatal depression that fell into either physical or psychosocial categories. Physical symptoms included feeling tired, being sleepy, loss of appetite, weight gain, headache, disorganised speech, not responding, inability to speak, unable to accomplish daily activities, over-sleeping, mood changes, shivering and unconsciousness. Psychosocial symptoms proposed by participants included feelings of worthlessness, sadness or sorrow, hopelessness, stress or anxiety, loneliness or self-isolation, dissatisfaction with health services, agoraphobia, inappropriate clothing, suicidal ideation and even suicide attempts, Many of the proposed symptoms reflected the more severe forms of depression, rather than milder depression which is most common during pregnancy or the postnatal period, with the rare exception of psychosis which can be severe but is easily diagnosed.

Mother with depression could show signs such as lethargic, not speaking correctly, unable to give their address, I know these. For example, they might not care for themselves or their foetus or infant. if they have HIV, they might not use condoms correctly. They might not be satisfied with their routine life, they might hate to do their usual activity, or they hate to speak to you. They might show feeling of worthlessness, suicide, sad, sorrow, tiredness, and they would not dress their clothes properly. (Female, aged 55 years)

In order to be able to provide services or to develop policies that would address perinatal depression, health administrators must be aware of what perinatal depression is. For some participants, this awareness was not demonstrated. For example, one participant indicated that they were not sure whether 
depression symptoms were different for perinatal women than the general population and was not able to mention general signs and symptoms that everybody with depression shows.

It is not specifically to mothers, that I do not know, but I can tell you the general signs and symptoms of depression that anybody with depression could show. (Male, aged 32 years)

\section{Health administrators' knowledge about the onset of symptoms and screening of perinatal depression}

Health administrators' knowledge about the specific time of onset of perinatal depression symptoms could help the development of protocols to initiate and implement screening programs at its most detectable time, but participants' knowledge or awareness about perinatal depression signs and symptoms was not specific. Their descriptions better reflected signs and symptoms of general depression. Participants commonly compared the extent of depression occurring during pregnancy and after birth. Some suggested that depression occurred more commonly during pregnancy than after birth. Another argued that depression rarely occurred during pregnancy but was more common after birth.

In some of the mothers, it might occur early like during their first trimester, but most of the time, it occurs at the end of the pregnancy. After birth, it is not common, but depression might occur in a few of the mothers. (Female, aged 32 years)

Sometimes depression might occur at the time of delivery though it was not reported in our institution. However, most of the time it occurred after delivery or during the postnatal period. (Male, aged 27 years).

Health care administrators require awareness about the timing of specific signs and symptoms of perinatal depression to detect it early and provide appropriate care for perinatal women. Concerningly, not all participants were able to identify the period by which signs and symptoms of perinatal depression might manifest:

Honestly speaking I do not really know the time by which these mothers start to show signs of depression or develop signs of depression. (Male, aged 32 years).

Participants' attitudes towards a specific time of screening for perinatal depression correlated with those about the time of occurrence of depression. Those who believed that depression is a problem of pregnancy perceived that screening should be conducted during any contact made with pregnant women during pregnancy, and they proposed the ANC visit as an appropriate time. Those who believed that depression was a problem of the postnatal period stated that depression screening should take place during the postnatal visit. In general, the best time proposed by many participants was at the time of ANC and PNC visits. This is justifiable because, while perinatal women present to health facilities for pregnancy and postnatal check-ups, in Ethiopia few postnatal women attend PNC visits. 
The screening should take place starting from the time of pregnancy until the postnatal period as we do not exactly know when the depression signs start to manifest. However, we give focus to postnatal depression as its prevalence is high. When we say postnatal, it includes from four to six weeks. (Male, aged 28 years).

Mainly if it (depression) should be screened, screening should be conducted during pregnancy when she comes for ANC follow up, when she comes for delivery, and thirdly after delivery when she comes for PNC follow up. (Male, aged 27 years).

Some participants indicated that screening for depression should be conducted at outpatient departments in health facilities. In the Ethiopian context, outpatient departments are areas in health facilities where patients receive immediate assessment and treatment. Most often, however, perinatal women attend maternal health clinics for issues associated with their physical health rather than visiting outpatient departments. This might suggest that participants were not adequately aware of perinatal depression.

I would be happy if screening could be done all the times. For example, in the outpatient department. Yet, we do not have psychiatry nurses in our health centre, and if we have one that can screen depression, this will help in reducing its burden. (Female, aged 55 years).

Other participants suggested that perinatal depression screening could be conducted during house to house visits. This idea was in reference to the use of health extension workers. These workers implement the Health Extension Program, which is a vertical program designed in Ethiopia in 2003 to improve access and affordability of primary health care services.

The screening of depression for mothers should be started at their home by health extension workers as the urban health extension workers' package addresses mental health issues. (Male, aged 41 years).

Disagreeing with the above, another participant working at a higher level in the healthcare system claimed that there was no evidence clearly showing that depression during pregnancy is common or that screening should be implemented. Furthermore, the participant stressed that the specific time at which this depression should be assessed and how to assess it is unknown.

There is nothing that says pregnant mothers are at risk of depression, and they should be assessed at this point. For example, I know that a pregnant mother who has suspected to have sexually transmitted diseases should be checked and treated after three months. But there is no study that recommended time by which depression during pregnancy should be assessed and treated. There is no screening procedure for depression in pregnancy. (Male, aged 52 years).

\section{Health administrators' knowledge about the consequences of untreated perinatal depression}

Health administrators' knowledge or awareness about consequences of untreated perinatal depression is crucial in order to give the matter priority in government planning. Participants expressed a number of 
views on the consequences of perinatal depression, ranging from serious infant and maternal health effects, including suicide, to social and family disruption. This would seem to indicate that an increased health focus on perinatal depression.

Almost all participants raised concerns that untreated depression would develop into a severe mental health disorder and potentially lead to suicide. However, the type of depression referred to would appear to be a severe form. Depression that occurs during the perinatal period is more commonly mild or moderate, which can be difficult to identify and diagnose. The severe form of depression that most participants discussed was severe psychotic disorders. It is possible they felt that perinatal depression, which is usually categorised as a non-psychotic disorder, could further develop into a psychotic disorder, as they stated:

If they stop taking their drugs, this might lead them to leave and sleep on roadsides or outside their house. (Female, aged 55 years)

Unless we diagnose and treat depression at an early stage, it might develop into an irreversible psychiatric problem such as dementia, which is unwanted. (Male, aged 29 years).

Most participants also suggested that untreated depression could lead to maternal suicide and death, proposing this could be through worsening to a severe form of health disorder that affects health seeking behaviour or makes women feel lonely and hopeless. Other participants suggested that depression directly leads to death because it is reported to be a major cause of death worldwide. Interviewed hospital workers stated:

Finally, if they are not treated from depression, they start to feel hopeless and, at last, go to suicide. When they had severe thought of hopelessness, they start asking about what is living for them. As they lose the meaning of life, living in this world would be nothing for them. So, they start with the idea of suicide, then they attempt and commit suicide at the end. (Male, aged 34 years).

The end consequence is death as depression by itself is a disease that cause death. (Male, aged 27 years)

The effect of perinatal depression on foetal development and birth outcomes was discussed. Participants explained the link in several ways. (a) Not using antidepressant medication correctly could affect foetal development and birth outcome; (b) genetic transmission of depression via placenta could lead the newborn baby to foetal distress and death; (c) depression could cause high blood pressure that would complicate the pregnancy and lead to abortion; and (d) depression could affect the nutritional status of the pregnant woman and foetal development.

Her foetus might have retardation, and in our culture, it is having been believed that, if the mother has depression, it also passes to the kid genetically. Based on my information or what I have heard, your foetus is healthy if you are healthy or your foetus is active if you are active. (Female, aged 55 years) 
During pregnancy, a mother in severe depression might not feed herself well; if she feels unmotivated or inactive, the foetus will not develop well, its growth would be restricted, or the pregnancy might end up in abortion. (Male, aged 26 years).

Adverse effects of perinatal depression on infant health (such as malnutrition, illnesses, and death) were suggested by the participants. Potential links between perinatal depression and infant morbidity that were proposed included reduced infant care, difficulty breastfeeding, and poor health-seeking behaviour. Perinatal depression as a cause of infant death was explained by the participants in two ways. The first is because of psychosis, which may present with sudden onset due to major hormonal imbalances after birth and lead to infanticide. This perception suggests a lack of clarity among study participants, given depression and psychosis are different conditions. The alternative theory proposed by participants was via maternal death due to depression, leaving the newborn orphaned and vulnerable to diminished care and development. There is little evidence for perinatal depression as a potential cause of mortality, which may further indicate low awareness among participants.

The mother starts to hate her infant and if she has no social support or if there is nobody around her, she might kill her infant by choking or by any other means. (Male, aged 34 years).

The mother might die from depression or other related conditions leaving the newborn orphaned, which affects cares to be given for the newborn that leads to poor growth or death. (Male, aged 27 years).

Nearly half of the participants identified the consequences of perinatal depression on social or family disruption through reduced income, disrupted relationships, and inability to work. It was suggested that mood swings and inability to communicate effectively because of depression symptoms would affect social and family interpersonal relationships. Similarly, because of decreased desire to work and perform routine activities in the home or outside, family income and relationships could be compromised. This could directly or indirectly lead to family or social disruption. Their behaviour change would also affect women's interaction with their social circle or family.

She might not correctly work what she has been working because of the depression. So, she might affect her family income as depression affects her work interest and productivity. (Male, aged 52 years).

Depression affects health of the mother and this indirectly affects the family. For instance, the mother might be unable to handle her family or not well functioning in performing routine activities in the family. (Male, aged 41 years).

\section{Participant's Views About Perinatal Depression Interventions}

This sub-theme highlighted health care administrators' views on how to care for perinatal women with depression. Two main views emerged from the analysis: (i) mothers with depression symptoms should be referred to hospitals because these are the only places where antipsychotic drugs are available, (ii) psychosocial support should be provided by health professionals, partners or families of mothers. Almost 
all participants recommended psychosocial support in the first place, with treatment for psychosis if the condition was severe.

For those who had depression, we provide social support by identifying possible sources of depression through psychological treatment or psychotherapy. If it (the depression) is severe enough, we provide them with psychotic drugs. And for mothers who have minor depression, their family should be informed or advised on how to provide them (the mothers) with support. (Male, aged 34 years)

\section{Cultural perspectives and lack of community (public) awareness about perinatal depression}

Low level of community health literacy or awareness, low health-seeking behaviours for mental health, and cultural norms about perinatal depression indirectly affected implementation of perinatal depression health services. Community awareness about perinatal depression and good health-seeking behaviour are very important to prevent and control the problem. Participants were concerned that women might seek out cultural and religious approaches to manage their depression rather than conventional health services by thinking of the disorder as evil and giving it other cultural meanings. Participants mentioned that public (community) awareness about mental health disorders, including depression, is low and people were not aware that such mental disorders are treatable. Participants raised the issue of community health literacy and poor health-seeking behaviour related to public cultural practices:

In fact, in addition to the lack of data, in our area where we are living, culturally, mothers would not prefer to go to health facilities when such disorder is happening to them. As depression is considered evil and demonic, most of the time, perinatal women prefer to go other places for service such as spiritual places to use holy water. (Female, aged 36 years)

The other barrier is community awareness on mental health condition or depression, they do not know that this condition is treatable. (Male, aged 52 years).

\section{Fragmented Healthcare System}

Three sub-themes emerged from interviews under the main theme of the fragmented healthcare system: (i) perinatal mental health policy and strategy; (ii) perinatal mental healthcare system; and (iii) government capacity, readiness, and prioritisation of perinatal depression

\section{Perinatal Mental Health Policy And Strategy}

The Ethiopian National Health Policy is an overarching document that provides guidance on how the country should address long-standing and emerging health priorities. This sub-theme assessed health administrators' views about how Ethiopian health policy addressed the issue of maternal mental health. Most participants expressed concerns that mental health services in general were compromised. Participants tried to underline the lack of attention to mental health services in Ethiopia by highlighting the lack of mental health policies and programs that should guide government activities. The following quotes reflect these concerns: 
So, I can say mental health issue and concerns are not receiving much attention from the top government. For example, if you try to contact the health bureau for issues concerning mental health, nobody gives you attention and services. Even when it is related to our ward (psychiatry ward). Generally, there is a lack of attention, starting from the policy framework, curriculum, and training. (Male, aged 34 years).

The absence of clear policy frameworks and programs might also affect appropriate training and allocation of human resources for mental health. The lack of properly organised mental health structures at different levels of the Ethiopian healthcare system may also stem from the lack of a national mental health policy and related programs. Despite being the second most populous region in the country, it does not have organised teams of mental health experts or mental health specialists able to plan and establish mental health services at the regional level. One participant said:

There is no mental health focal person at the regional level. If there is no focal person, nothing would be done. But if there is a focal person, he/she can plan, deal, arrange ... (Male, aged 34 years)

The general national mental health strategy developed in 2012 (50) did not specifically address mental health need of vulnerable groups such as perinatal women, peoples with disabilities, and incarcerated people. Nearly all participants confirmed that the available national mental health strategy did not specifically focus on the diagnosis and treatment of perinatal depression. The following quote demonstrates this:

We do have a general country-level mental health strategy, but it is not specified for age, sex, or specifically designed for pregnant mothers, and it is a general approach. (Male, aged 34 years)

\section{Perinatal Mental Healthcare System}

A healthcare system is the organisation of institutions, departments, health professionals and resources that are essential to deliver all healthcare services required to meet the needs of a given population. To undertake screening and manage perinatal depression, therefore, there should be an established and clear healthcare system at all levels that can address the 'who, how, where, when and what should be done' questions. The main barrier, agreed by almost interviewees, was the lack of an established system to prevent, screen, and treat perinatal depression. As one participant described:

The system might be challenging; for example, it would be difficult to say that clinicians in the area of ANC can know and screen depression. If you go to other health facilities or such clinics and ask how they are screening pregnant women with depression, they would tell, we use nothing. This itself can be part of the system. So, if the mother has depression during pregnancy or after delivery, she might be missed or misdiagnosed because of the lack of provision to identify the problem. And as a psychiatry clinic leader, if I want to create a system like if I want to assign a psychiatrist in ANC or PNC department to screen depression, nobody allows me, and this is part of a system too. (male, aged 28 years)

\section{Government Capacity, Readiness, And Prioritisation Of Perinatal Depression}


This sub-theme includes healthcare administrators' perspectives of government capacity, readiness, and priority for screening and managing perinatal depression at health service delivery points. The actual activities implemented at service delivery level to address perinatal depression were explored. All those interviewed agreed that there was no effective or adequate guidance for managing perinatal depression in health facilities at different levels of healthcare delivery. One health administrator from a health centre said:

Yes, I can say the Federal Ministry of Health (FMOH) has no initiative, plan, and readiness to screen, treat, prevent, and control perinatal depression in the healthcare system. So, if FMOH has no such initiatives, it isn't very easy, or it is obvious that health structure beneath the FMOH would have no such initiative as every activity we are doing is based on the FMOH direction. (Female, aged 36 years)

Participants identified reasons for such little attention due to: (i) reduced priority of perinatal mental health; (ii) lack of knowledge about the burden and consequences of perinatal depression; (iii) lack of training of health professionals in screening depression; and (iv) high patient loads.

\section{i. Reduced priority of perinatal mental health}

Ethiopia is a low-income country, which means that resources are limited, and it is not possible to tackle every health problem. As such, a focus on priority health conditions is considered mandatory. Priority has been given to conditions that are the leading causes of mortality and morbidity. It has been believed that perinatal depression is not a leading cause of mortality and morbidity in Ethiopia, compared with other communicable and non-communicable diseases of pregnancy and childbirth. One participant mentioned the following to show that perinatal depression is not a priority issue for the government:

Because of many other communicable and non-communicable diseases that need fast attention, perinatal depression is not given a high priority. To reduce maternal and child mortality, hypertension, obstructed labour and infections causes higher numbers of deaths than depression. As such, if we strictly work on these issues, we might bring more changes in maternal health. We are also one of the lowincome countries with limited resources, and the Ministry of Health might believe that more attention should be given for such conditions than depression. As you see, due to there being many health issues in the country, the government prioritises and focuses on interventions that benefit most of the women. (Male, aged 29 years).

\section{ii. Lack of knowledge about the burden and consequences}

As was concluded in the previous section (section 7.3.1), health administrators' knowledge about the burden and consequences of untreated perinatal depression was generally low. More importantly, health administrators working at higher levels of the healthcare system, where policy and strategy are developed, were found to have less knowledge than those working at lower levels of the healthcare system. This would significantly affect health administrators' motivation towards prioritising, planning, and initiating perinatal depression health services. There also appeared to be insufficient information 
about the consequences of perinatal depression to make perinatal depression a priority focus of the government, as one participant working at a higher level of the health care system said:

As I told you about this, there are no separate and specific activities. The primary thing about perinatal depression is that we do not consider it as a public health problem of significance, and we do not have data about it. It has not been the forefront of public health priority threats in this region. (Female, aged 50 years)

\section{iii. Health professionals lack of training in screening for depression}

The question about who should be responsible for screening needs to be clearly addressed in the healthcare system and enough personnel should be trained and made available in all health facilities that are expected to intervene in perinatal depression. This comes back to perinatal depression not being included as a priority health item in the country. Human resource development is a main issue for any perinatal mental health strategy and plan, but without such plans, attention given to human workforce development would be compromised. One participant working as a coordinator at a higher level of the health care system said:

Starting screening service is not easy. We do not have health professionals who trained in mental health. It needs a psychiatrist to screen and manage perinatal depression, and these professionals are minimal, including those who are in schools. So, we do not have trained professionals now, and it is challenging. (Male, aged 52 years)

\section{iv. High patient load}

Another barrier described by participants as a reason for government giving low priority to perinatal depression was high patient loads in health facilities because of other morbidities. As explained in a previous section, Ethiopian health facilities always are required to treat large numbers of patients with various acute and chronic health problems. At the same time, the country is placing increased demands of health professionals in health facilities. This might affect perinatal depression screening and management because of the time required for even relatively brief consultations with perinatal women. One interviewee said:

As this is a tertiary hospital, every client comes for better service. As such, due to time limitation, it is not easy to rule out additional problems like depression. (Male, aged 29 years)

\section{Enablers for or opportunities to start perinatal depression screening services}

This theme presents health system administrators' views about the current situation of mental health services and the opportunities for perinatal depression screening services in Ethiopia. Participants described mental health services as being compromised and only focused on treating those who were presenting to health facilities with severe problems. They further added that there was no system for early detection and prevention of mental health disorders in the community. However, participants identified 
three potential opportunities or enablers that could help the Ethiopian healthcare system to start screening for depression in perinatal women $d$ and to establish effective management of it. These opportunities were: the introduction of the WHO Mental Health Gap (mhGap) (51) action program; health professionals' commitment; and simplicity of the screening program.

The mhGap action program is an international initiative developed by the WHO to fill the mental health service gap between what is available and what is urgently needed to reduce the burden of mental disorders. Participants suggested that the introduction of the mhGap initiative could potentially provide an opportunity to start and expand maternal mental health interventions in Ethiopia.

Until now, the available policy does not allow non-psychiatry health professionals to provide psychiatric services. Mental health services have been limited at the hospital level. But nowadays, because of the findings by WHO that the burden is becoming high, mental health is getting attention. One psychiatrist used to serve a population of 100,000. These days, health professionals are being trained, protocols are being under preparation, and activities have been started under MhGap initiatives to bring mental health services to health centre level. (Male, aged 52 years)

Health professionals' commitment would also be needed to enable screening for perinatal depression in health facilities. Participants hoped that screening perinatal women for depression would not be more challenging than what they currently do for everyone visiting a health facility. Health administrators mentioned that health professionals such as themselves were highly motivated to make screening available and to manage perinatal depression if the health system could be made ready for this. One participant stated that it is possible to make screening for perinatal depression available if the environment is ready:

Simplicity of the screening activity was another potential enabler for instituting screening in health facilities. Participants suggested that screening would not be difficult relative to other clinical assessments that may require laboratory facilities, and additional skilled professionals. Using a brief screening tool, screening for depression might require a maximum of 15 minutes to implement. Similarly, additional physical space would not be required for screening because assessments could be undertaken in the same rooms where ANC and PNC services are delivered. One participant stated that health professionals are motivated and committed to undertake screening, and the only problem is lack of skill and a supportive system.

Yes, maybe we would screen and refer, this would be simple. I can see it is possible to screen pregnant and postnatal women with depression. I saw a Master's student who did the screening in our health centre, so it is also possible as you are also doing the screening as well. (Female, aged 50 years)

\section{Discussion}

This study explored barriers and enablers to implementing perinatal depression health services in Ethiopia. Although there was reporting of initiatives to address mental health service issues including the 
WHO Mental Health Gap (mhGap action program), further actions seemed to be needed to achieve effective implementation of such initiatives. For example, the current level of mental health literacy of policy makers and healthcare system leaders and the organisational context of the Ethiopian healthcare system seemed to be one of the bottlenecks for effective mhGap action program implementation (52). Specifically, the following barriers were identified in the current study: (i) At the individual level, health administrators have little knowledge about perinatal depression risk factors, symptoms, optimal time for screening, treatment options, and the potential consequences of depression. (ii) At the socio-cultural level, there is low awareness about perinatal depression in the community, reduced health-seeking behaviours and prohibitive cultural norms; (iii) Organisational level barriers include lack of government capacity, readiness, and priority to screen and manage perinatal depression; (iv) Structural level barriers include lack of perinatal mental health policies and strategies, and transparency in the healthcare system. In addition, the study found that the introduction of the new mhGap action program, health professionals' commitment, and simplicity of screening program could represent opportunities for or enablers of implementation of perinatal mental health services.

Health administrators' low knowledge about perinatal depression risk factors, signs and symptoms, time of screening, health consequences and interventions are identified as individual level barriers for perinatal depression service implementation. Consistent with our findings, health administrators' low level of knowledge in defining and conceptualising perinatal depression emerged as one of the barrier to diagnosis and treatment of perinatal depression in other studies $(53,54)$. Similarly, health professionals' low level of knowledge about signs and symptoms of perinatal depression and difficulties in identifying women with perinatal depression have been previously reported as barriers $(55,56)$. This low level of knowledge about perinatal depression among health administrators and health professionals knowledge could constitute a major barrier for effective integration of maternal mental health and routine health services at the primary health care level (57). Good mental health literacy is important for improving health, healthcare systems, and health policy $(58,59)$ and this should be a priority issue for health professionals working at administrative level. As such, previously conducted reviews in low- and middleincome countries have highlighted the need to build capacity of policy makers and planners to help strengthen mental healthcare systems $(60,61)$.

Study participants identified low community awareness about perinatal depression, health-seeking behaviours, and cultural norms as potential socio-cultural level barriers for implementation of perinatal depression healthcare services. As described by participants, participants did not attend health services because cultural norms considered depression as 'evil' or 'demonic' rather than as a health problem that could be treatable. These norms are similar to cultural and community level barriers to access for mental health services identified in a systematic review and meta-synthesis of qualitative studies in the UK (34) and elsewhere (62-64). Similarly, low community mental health literacy and a lack of models for multisectoral collaboration between traditional and religious healers were also reported as key challenges for implementing an integrated mental health care in low- and middle-income countries (65). As such, health information on common perinatal mental health disorders should be provided for perinatal mothers in the community through health extension workers using a culturally sensitive approach. 
Furthermore, creation of awareness about the differences between normal pregnancy feelings and perinatal depression symptoms might be required to increase health seeking behaviour of women. Nonetheless, simply increasing community awareness in a healthcare system where perinatal mental health services are not well organised or functioning, is likely to have only limited success.

Lack of government capacity, readiness, and priority for screening and managing perinatal depression were organisational level barriers to perinatal mental health interventions discussed by study participants. High patient loads, lack of trained workforce and resources such as screening tools, guidelines, working manuals, and treatment protocols were potentially linked to lack of government capacity, readiness, and priority. These barriers should be addressed if an efficient depression screening and management program is to be established in the country. Our findings were consistent with organisational level factors reported by Smith (34) from a multi-level model of barriers to perinatal mental health interventions. Staff workloads and lack of time with health professionals for health service linkage were reported to be barriers to screening and referral for perinatal depression in high-income countries (66-68). Furthermore, lack of training in mental health care, resources, and locally validated screening tools, together with health professionals' negative attitudes towards screening were reported as barriers in systematic reviews of qualitative studies (69-72). Insufficient or lack of training, unexplained long waiting times, inconsistent screening practices, and not knowing the scope of practice were mentioned as common barriers for identification and treatment of perinatal mental disorders in other systematic reviews $(73,74)$. Low levels of funding have also been reported as a key challenge for sustainable mental health services because of widespread poverty and inequalities of access in low-income countries (75). As such, it has been suggested that both perceived and established barriers associated with client or service providers should be addressed to create a suitable environment for implementing and maintaining mental health continuity of care in health facilities $(76,77)$.

Lack of perinatal mental health policies and strategies were proposed as structural level barriers to implementation of perinatal depression health services in Ethiopia. Lack of clarity in policies about how to screen for perinatal depression, and lack of clear pathways of care for those who had symptoms, were reported as structural level barriers to perinatal mental health interventions in a systematic review of qualitative studies (34). The health policy of the government of Ethiopia has a central focus on preventing and treating diseases (78), but it does not address the issue of perinatal depression. Moreover, in the National Mental Health Strategy developed in 2012, only two paragraphs were devoted to reproductive mental health. There is also a lack of clarity on what should be done and how, and, generally, issues with its implementation have not been well addressed (50). For example, a situational analysis in five low- and middle-income countries including Ethiopia revealed a lack of evidence for feasible detection and treatment strategies for mental health disorders (72). The probable reason was a lack of priority that possibly emanated from lack of information or data on the burden and consequences of perinatal depression.

The absence of clear pathways in the healthcare system was the other most commonly discussed structural level barrier to implementation of perinatal depression services. This is consistent with

Page $21 / 32$ 
structural barriers reported in a multi-level model of barriers of perinatal mental health interventions in high-income countries (34). Perinatal women with depression symptoms in Malawi proposed that strengthening the healthcare delivery system was the most important issue to address their needs (79). Lack of clear work structures or systems for identifying perinatal women with depression and broken referral pathways were identified as important structural barriers to perinatal mental health intervention in a systematic review (62). In another study, structural or system level barriers to perinatal mental health implementation included complex and unclear pathways such as unlinked services, lack of continuity of care, scarcity of referral resources, and complex bureaucratic procedures (73).

Several studies have indicated that perinatal depression is both a complication (80) and/or a consequence of complications in pregnancy (81-83). Perinatal depression could be a cause of complications that significantly affect pregnancy outcomes $(76,84,85)$, child development, and higher maternal risk of subsequent psychological morbidities $(72,86-89)$. Screening and providing psychotherapy to perinatal women at higher risk of depression would not significantly increase the overall cost of health expenditure in the health care system, and its benefit would outweigh the cost (9092). Antenatal and postnatal depression prevalences as high as $32 \%$ (93) and $34 \%$ (5), respectively have been reported in Ethiopia, and perinatal depression is documented as having multifaceted consequences for children $(8,94)$ and mothers $(95)$. In this context, the American Psychiatric Association (96), College of Obstetrics and Gynaecology (97), US Preventive Service Task Force (98), and the World Health Organization (99) have recommended screening and treatment. The effectiveness of screening and preliminary counselling interventions in preventing perinatal depression has also been documented in recent literature (90-92). Given this evidence, it is important for the government of Ethiopia to consider the integration of perinatal depression into routine maternal health services by overcoming the current complexities (100). The following opportunities and enablers that were discussed by study participants might help to simplify this integration.

Health administrators in this study discussed the introduction of the new mhGap action program, health professionals' commitment, and simplicity of screening programs as enablers or facilitators for perinatal mental health service implementation. This is in line with a qualitative study that explored health professionals' positive attitude towards the integration of mental health services as a facilitator for the acceptability of mental health services for perinatal women in Ethiopia (101). The mhGap action program prioritises the integration of mental health services into primary care services, and maternal mental health has been considered as an essential component of this integration (51). The mhGap initiative aims to train and use generalist nurses to diagnose and treat mental health disorders at the health centre level, which could potentially help to overcome shortage of human resources. It also aims to increase mental health awareness in the community to improve early detection and treatment. Perinatal women are more likely to be screened when health professionals are sensitive and interested, when there is continuity of care, and women are reassured that depression screening is part of a routine antenatal care $(63,102-$ 104). Similarly, both qualitative and quantitative studies have shown a high level of acceptance of perinatal depression screening by health providers and perinatal patients $(64,66,105,106)$. The simplicity of screening programs adds support because any health professional can undertake screening, 
or the screening tool could be self-administered by mothers (107), assuming the screening tool is validated and culturally acceptable $(108,109)$.

There are limitations that should be born in mind during the interpretation and use of these findings for decision making. Some of the younger participants had limited experience, which could affect an in-depth understanding of health policies, programs, and strategies of the country in general and perinatal depression in particular. Although participants were assured of the confidentiality, it is possible that potential introduction of social desirability bias existed with some participants being concerned of their responses being communicated to higher officials. However, to reduce these issues, the interviewer assured the confidentiality of the information they provided, interview was undertaken in private office, and clarified that the role of the interviewer was interviewing and would not have any connection with the health delivery system. Despite these limitations, this is the first attempt to explore barriers to and enablers of perinatal depression service implementation in Ethiopia. As such, the findings will therefore be useful to health planners, researchers, partners and, ultimately, perinatal women and their infants.

\section{Conclusions and recommendations}

This study aimed to identify barriers and enablers to the provision of perinatal mental health services in Ethiopia. The study identified health administrators' low literacy about perinatal depression as an individual level barrier; community low awareness, health-seeking behaviours and cultural norms about perinatal depression as socio-cultural level barriers; lack of government capacity, readiness, and priority for screening and managing perinatal depression as organisational level barriers; and lack of perinatal mental health policies, strategies, and healthcare systems as structural level barriers for perinatal mental health service implementations in Ethiopia. On the other hand, introduction of the new mhGap action program, health professionals' commitment to providing effective services, and simplicity of screening programs were identified as potential enablers or facilitators for perinatal mental health service implementation. Building the capacity of policy makers and planners should be a first step in mental healthcare system building related to perinatal depression in Ethiopia. Strengthening the mental healthcare system and governance to produce clear mental health policies, programs, strategies, structures, and legislative framework is mandatory for effective integration of maternal mental health care with routine maternal health services in Ethiopia.

\section{Abbreviations}

WHO: World Health Organization

DSM-IV: Diagnostic and Statistical Manual of Mental Disorder

AND: Antenatal Depression

EPDS: Edinburgh Postnatal Depression Scale

SBRC: Social and Behavioral Research Ethics Committee 


\section{Declarations}

\section{Ethics approval and consent to participate}

The research was approved both by the Social and Behavioural Research Ethics Committee of the Flinders University, Australia (reference number 7959, 2018) and the Institutional Review Board of the University of Gondar (reference number O/V/P/RCS/05/1601, 2018). All methods were carried out in accordance with relevant guidelines and regulations. Study participants were informed about the purpose, objectives, and their right to decline participation or withdraw from participation at any time. Informed consent was obtained from each participant. Privacy and confidentiality were maintained throughout the study.

\section{Consent for publication}

Not applicable

\section{Availability of data statement}

The datasets used and/or analysed during the current study available from the corresponding author on reasonable request as this is part of a $\mathrm{PhD}$ work.

\section{Competing interest}

None to declare

\section{Funding}

This research received no specific grant from any funding agency in the public, commercial or not-forprofit sectors.

\section{Author contributions}

Conceptualization: AFD, LM, ERM

Formal analysis: AFD

Investigation: AFD, LM, ERM, TA

Methodology: AFD, LM, ERM, TA

Software: AFD

Validation: AFD, LM, ERM, TA

Writing original draft: AFD 
Writing review \& editing: AFD, LM, ERM, TA

\section{Acknowledgments}

We are grateful to all study participants, supervisors and health administrators at different level and their family.

\section{References}

1. Dadi AF, Miller ER, Bisetegn TA, Mwanri L. Global burden of antenatal depression and its association with adverse birth outcomes: an umbrella review. BMC Public Health. 2020;20(1):173.

2. Fekadu Dadi A, Miller ER, Mwanri L. Antenatal depression and its association with adverse birth outcomes in low and middle-income countries: A systematic review and meta-analysis. PLOS ONE. 2020;15(1):e0227323.

3. Zegeye A, Alebel A, Gebrie A, Tesfaye B, Belay YA, Adane F, et al. Prevalence and determinants of antenatal depression among pregnant women in Ethiopia: a systematic review and meta-analysis. BMC pregnancy and childbirth. 2018;18(1):462.

4. Azale T, Fekadu A, Hanlon C. Postpartum depressive symptoms in the context of high social adversity and reproductive health threats: a population-based study. Int J Ment Health Syst. 2018;12:42.

5. Kerie S, Menberu M, Niguse W. Prevalence and associated factors of postpartum depression in Southwest, Ethiopia, 2017: a cross-sectional study. BMC Res Notes. 2018;11(1):623.

6. Bitew T, Hanlon C, Kebede E, Honikman S, Fekadu A. Antenatal depressive symptoms and perinatal complications: a prospective study in rural Ethiopia. BMC psychiatry. 2017;17(1):301-.

7. Lewis AJ, Austin E, Galbally M. Prenatal maternal mental health and fetal growth restriction: A systematic review. Journal of Developmental Origins of Health and Disease. 2016;7(4):416-28.

8. Aktar E, Qu J, Lawrence PJ, Tollenaar MS, Elzinga BM, Bogels SM. Fetal and Infant Outcomes in the Offspring of Parents With Perinatal Mental Disorders: Earliest Influences. Front Psychiatry. 2019;10:391.

9. Donaldson F. Postnatal depression and infant feeding: A review of the evidence. British Journal of Midwifery. 2011;19(10):619-24.

10. de Jager E, Skouteris H, Broadbent J, Amir L, Mellor K. Psychosocial correlates of exclusive breastfeeding: a systematic review. Midwifery. 2013;29(5):506-18.

11. Mekonnen H, Medhin G, Tomlinson M, Alem A, Prince M, Hanlon C. Impact of maternal common mental disorders on child educational outcomes at 7 and 9 years: a population-based cohort study in Ethiopia. BMJ Open. 2018;8(1):e018916.

12. Myers $S$, Johns SE. Postnatal depression is associated with detrimental life-long and multigenerational impacts on relationship quality. PeerJ. 2018;6:e4305-e. 
13. Gausia K, Moran AC, Ali M, Ryder D, Fisher C, Koblinsky M. Psychological and social consequences among mothers suffering from perinatal loss: perspective from a low income country. BMC Public Health. 2011;11(1):451.

14. Saxena S, Funk M, Chisholm D. Comprehensive mental health action plan 2013-2020. EMHJEastern Mediterranean Health Journal. 2015;21(7):461-3.

15. Lund C, Tomlinson M, De Silva M, Fekadu A, Shidhaye R, Jordans M, et al. PRIME: a programme to reduce the treatment gap for mental disorders in five low-and middle-income countries. PLoS medicine. 2012;9(12).

16. Organization WH. mhGAP intervention guide for mental, neurological and substance use disorders in non-specialized health settings: mental health Gap Action Programme ( mhGAP)-version 2.0: World Health Organization; 2016.

17. Dua T, Barbui C, Clark N, Fleischmann A, Poznyak V, van Ommeren M, et al. Evidence-based guidelines for mental, neurological, and substance use disorders in low-and middle-income countries: summary of WHO recommendations. PLoS medicine. 2011;8(11).

18. Semrau M, Evans-Lacko S, Alem A, Ayuso-Mateos JL, Chisholm D, Gureje O, et al. Strengthening mental health systems in low- and middle-income countries: the Emerald programme. BMC medicine. 2015;13(1):79.

19. Hailemariam M, Fekadu A, Medhin G, Prince M, Hanlon C. Equitable access to mental healthcare integrated in primary care for people with severe mental disorders in rural Ethiopia: a communitybased cross-sectional study. International Journal of Mental Health Systems. 2019;13(1):78.

20. Azale T, Fekadu A, Hanlon C. Treatment gap and help-seeking for postpartum depression in a rural African setting. BMC Psychiatry. 2016;16(1):196.

21. Rodrigues M, Patel V, Jaswal S, De Souza N. Listening to mothers: qualitative studies on motherhood and depression from Goa, India. Social science \& medicine. 2003;57(10):1797-806.

22. Nakku JEM, Okello ES, Kizza D, Honikman S, Ssebunnya J, Ndyanabangi S, et al. Perinatal mental health care in a rural African district, Uganda: a qualitative study of barriers, facilitators and needs. BMC Health Services Research. 2016;16(1):295.

23. Berhane $Y$, Gossaye $Y$, Emmelin $M$, Hogberg U. Women's health in a rural setting in societal transition in Ethiopia. Social Science \& Medicine. 2001;53(11):1525-39.

24. Hanlon C, Whitley R, Wondimagegn D, Alem A, Prince M. Postnatal mental distress in relation to the sociocultural practices of childbirth: an exploratory qualitative study from Ethiopia. Social science \& medicine. 2009;69(8):1211-9.

25. Organization WH. Global action plan for the prevention and control of noncommunicable diseases 2013-2020: World Health Organization; 2013.

26. Rahman A, Surkan PJ, Cayetano CE, Rwagatare P, Dickson KE. Grand challenges: integrating maternal mental health into maternal and child health programmes. PLoS medicine. 2013;10(5).

27. Baron EC, Hanlon C, Mall S, Honikman S, Breuer E, Kathree T, et al. Maternal mental health in primary care in five low- and middle-income countries: a situational analysis. BMC health services research. 
2016;16:53-.

28. Thornicroft G, Alem A, Dos Santos RA, Barley E, Drake RE, Gregorio G, et al. WPA guidance on steps, obstacles and mistakes to avoid in the implementation of community mental health care. World Psychiatry. 2010;9(2):67-77.

29. de Savigny D, Adam T. Systems thinking for health system strengthening. In: Alliance for health policy and systems research. Geneva: WHO; 2009.

30. Lund C, Tomlinson M, De Silva M, Fekadu A, Shidhaye R, Jordans M, et al. PRIME: a programme to reduce the treatment gap for mental disorders in five low- and middle-income countries. PLoS medicine. 2012;9(12):e1001359-e.

31. Semrau M, Evans-Lacko S, Alem A, Ayuso-Mateos JL, Chisholm D, Gureje O, et al. Strengthening mental health systems in low- and middle-income countries: the Emerald programme. BMC medicine. 2015;13:79-.

32. Hanlon C, Alem A, Lund C, Hailemariam D, Assefa E, Giorgis TW, et al. Moving towards universal health coverage for mental disorders in Ethiopia. International Journal of Mental Health Systems. 2019;13(1):11.

33. Hanlon C, Eshetu T, Alemayehu D, Fekadu A, Semrau M, Thornicroft G, et al. Health system governance to support scale up of mental health care in Ethiopia: a qualitative study. International Journal of Mental Health Systems. 2017;11(1):38.

34. Sambrook Smith M, Lawrence V, Sadler E, Easter A. Barriers to accessing mental health services for women with perinatal mental illness: systematic review and meta-synthesis of qualitative studies in the UK. BMJ Open. 2019;9(1):e024803.

35. FDRE. Constitution of the Federal Democratic Republic of Ethiopia. Federal Negarit Gazeta. 1995;1(1):73-142.

36. Higginbottom G, Liamputtong P. Participatory qualitative research methodologies in health: Sage; 2015.

37. Bazeley P. Qualitative data analysis: Practical strategies: Sage; 2013.

38. Hennink M, Hutter I, Bailey A. Qualitative research methods: Sage; 2010.

39. Creswell JW. Research Design: Qualitative. Quantitative, and mixed methods. 2003.

40. Braun V, Clarke V. Successful qualitative research: A practical guide for beginners: sage; 2013.

41. Creswell JW, Hanson WE, Clark Plano VL, Morales AJTcp. Qualitative research designs: Selection and implementation. 2007;35(2):236-64.

42. Liamputtong PJHPJoA. Qualitative data analysis: conceptual and practical considerations. 2009;20(2):133-9.

43. Welsh E, editor Dealing with data: Using NVivo in the qualitative data analysis process. Forum qualitative sozialforschung/Forum: qualitative social research; 2002.

44. Vaismoradi M, Turunen $\mathrm{H}$, Bondas T. Content analysis and thematic analysis: Implications for conducting a qualitative descriptive study. Nurs Health Sci. 2013;15(3):398-405. 
45. Creswell JW, Creswell JD. Research design: Qualitative, quantitative, and mixed methods approaches: Sage publications; 2017.

46. Pope C, Ziebland S, Mays N. Analysing qualitative data. BMJ : British Medical Journal. 2000;320(7227):114-6.

47. Srivastava P, Hopwood N. A Practical Iterative Framework for Qualitative Data Analysis. International Journal of Qualitative Methods. 2009;8(1):76-84.

48. Smith J, Firth J. Qualitative data analysis: the framework approach. 2011;18(2):52-62.

49. KLEINBAUM DG, MORGENSTERN H, KUPPER LL. SELECTION BIAS IN EPIDEMIOLOGIC STUDIES12. American Journal of Epidemiology. 1981;113(4):452-63.

50. Bradshaw C, Atkinson S, Doody O. Employing a Qualitative Description Approach in Health Care Research. Glob Qual Nurs Res. 2017;4:2333393617742282-.

51. World Health Organization. mhGAP: Mental Health Gap Action Programme: scaling up care for mental, neurological and substance use disorders. 2008.

52. Petersen I, Marais D, Abdulmalik J, Ahuja S, Alem A, Chisholm D, et al. Strengthening mental health system governance in six low- and middle-income countries in Africa and South Asia: challenges, needs and potential strategies. Health Policy and Planning. 2017;32(5):699-709.

53. Place JMS, Billings DL, Blake CE, Frongillo EA, Mann JR, Decastro F. Conceptualizations of postpartum depression by public-sector health care providers in Mexico. Qualitative Health Research. 2015;25(4):551-68.

54. Buist A, Bilszta J, Milgrom J, Barnett B, Hayes B, Austin MP. Health professional's knowledge and awareness of perinatal depression: Results of a national survey. Women and Birth. 2006;19(1):11-6.

55. Edge D. Falling through the net - black and minority ethnic women and perinatal mental healthcare: health professionals' views. Gen Hosp Psychiatry. 2010;32(1):17-25.

56. Nasir LS, Al-Qutob R. Barriers to the diagnosis and treatment of depression in Jordan. A nationwide qualitative study. J Am Board Fam Pract. 2005;18(2):125-31.

57. Ng'oma M, Bitew T, Kaiyo-Utete M, Hanlon C, Honikman S, Stewart RC. Perinatal mental health around the world: priorities for research and service development in Africa. BJPsych International.14.

58. Hernandez LM. Health literacy: Improving health, health systems, and health policy around the world: Workshop summary: National Academies Press; 2013.

59. Paasche-Orlow MK, Wolf MS. The causal pathways linking health literacy to health outcomes. Am J Health Behav. 2007;31 Suppl 1:S19-26.

60. Keynejad R, Semrau M, Toynbee M, Evans-Lacko S, Lund C, Gureje O, et al. Building the capacity of policy-makers and planners to strengthen mental health systems in low- and middle-income countries: a systematic review. BMC health services research. 2016;16(1):601-.

61. Petersen I, Lund C, Stein DJ. Optimizing mental health services in low-income and middle-income countries. Current opinion in psychiatry. 2011;24(4):318-23. 
62. Viveiros CJ, Darling EK. Barriers and facilitators of accessing perinatal mental health services: The perspectives of women receiving continuity of care midwifery. Midwifery. 2018;65:8-15.

63. Kingston D, Austin MP, Heaman M, McDonald S, Lasiuk G, Sword W, et al. Barriers and facilitators of mental health screening in pregnancy. J Affect Disord. 2015;186:350-7.

64. Kingston DE, Biringer A, McDonald SW, Heaman MI, Lasiuk GC, Hegadoren KM, et al. Preferences for Mental Health Screening Among Pregnant Women: A Cross-Sectional Study. American journal of preventive medicine. 2015;49(4):e35-43.

65. Hanlon C, Luitel NP, Kathree T, Murhar V, Shrivasta S, Medhin G, et al. Challenges and opportunities for implementing integrated mental health care: a district level situation analysis from five low- and middle-income countries. PLoS One. 2014;9(2):e88437.

66. Nagle U, Farrelly M. Women's views and experiences of having their mental health needs considered in the perinatal period. Midwifery. 2018;66:79-87.

67. Byatt N, Simas TA, Lundquist RS, Johnson JV, Ziedonis DM. Strategies for improving perinatal depression treatment in North American outpatient obstetric settings. J Psychosom Obstet Gynaecol. 2012;33(4):143-61.

68. Kim JJ, La Porte LM, Corcoran M, Magasi S, Batza J, Silver RK. Barriers to mental health treatment among obstetric patients at risk for depression. Am J Obstet Gynecol. 2010;202(3):312.e1-5.

69. January J, Chimbari MJ. Opportunities and obstacles to screening for perinatal depression among women in Zimbabwe: A narrative review of literature. S Afr J Psychiatr. 2018;24:1127-.

70. Goldin Evans M, Phillippi S, Gee RE. Examining the Screening Practices of Physicians for Postpartum Depression: Implications for Improving Health Outcomes. Womens Health Issues. 2015;25(6):703-10.

71. Glasser S, Levinson D, Bina R, Munitz H, Horev Z, Kaplan G. Primary Care Physicians' Attitudes Toward Postpartum Depression: Is It Part of Their Job? Journal of primary care \& community health. 2016;7(1):24-9.

72. Baron EC, Hanlon C, Mall S, Honikman S, Breuer E, Kathree T, et al. Maternal mental health in primary care in five low- and middle-income countries: A situational analysis. BMC Health Services Research. 2016;16(1).

73. Bayrampour $\mathrm{H}$, Hapsari AP, Pavlovic J. Barriers to addressing perinatal mental health issues in midwifery settings. Midwifery. 2018;59:47-58.

74. Viveiros CJ, Darling EK. Perceptions of barriers to accessing perinatal mental health care in midwifery: A scoping review. Midwifery. 2019;70:106-18.

75. Chisholm D, Docrat S, Abdulmalik J, Alem A, Gureje O, Gurung D, et al. Mental health financing challenges, opportunities and strategies in low- and middle-income countries: findings from the Emerald project. BJPsych Open. 2019;5(5):e68.

76. Abazarnejad T, Ahmadi A, Nouhi E, Mirzaee M, Atghai M. Effectiveness of psycho-educational counseling on anxiety in preeclampsia \%J Trends in Psychiatry and Psychotherapy. 2019. 
77. WHO. WHO recommendations on antenatal care for a positive pregnancy experience. Geneva: World Health Organization. 2016.

78. Federal Democratic Republic of Ethiopia Ministry of Health: HEALTH POLICY OF THE TRANSITIONAL GOVERNMENT OF ETHIOPIA. Addis Ababa. 1993.

79. Ng'oma M, Meltzer-Brody S, Chirwa E, Stewart RC. "Passing through difficult times": Perceptions of perinatal depression and treatment needs in Malawi - A qualitative study to inform the development of a culturally sensitive intervention. PLOS ONE. 2019;14(6):e0217102.

80. Dubreucq M, Jourdan S, Poizat A, Dubreucq J. Ressenti des sages-femmes dans la prise en charge en suites de couche des patientes avec troubles psychiques sévères : une analyse qualitative. L'Encéphale. 2019.

81. Koutra K, Vassilaki M, Georgiou V, Koutis A, Bitsios P, Kogevinas M, et al. Pregnancy, perinatal and postpartum complications as determinants of postpartum depression: the Rhea mother-child cohort in Crete, Greece. Epidemiol Psychiatr Sci. 2018;27(3):244-55.

82. Blom E, Jansen $P$, Verhulst $F$, Hofman $A$, Raat $H$, Jaddoe V, et al. Perinatal complications increase the risk of postpartum depression. The Generation R Study. 2010;117(11):1390-8.

83. Asghari E, Faramarzi M, Mohammmadi AK. The Effect of Cognitive Behavioural Therapy on Anxiety, Depression and Stress in Women with Preeclampsia. J Clin Diagn Res. 2016;10(11):QC04-QC7.

84. Yu Y, Zhang S, Wang G, Hong X, Mallow EB, Walker SO, et al. The combined association of psychosocial stress and chronic hypertension with preeclampsia. Am J Obstet Gynecol. 2013;209(5):438.e1-.e12.

85. Grigoriadis S, Graves L, Peer M, Mamisashvili L, Tomlinson G, Vigod SN, et al. Maternal Anxiety During Pregnancy and the Association With Adverse Perinatal Outcomes: Systematic Review and Meta-Analysis. J Clin Psychiatry. 2018;79(5).

86. Spyridou A, Schauer M, Ruf-Leuschner M. Prenatal screening for psychosocial risks in a high riskpopulation in Peru using the KINDEX interview. BMC pregnancy and childbirth. 2016;16(1):13.

87. Zijlmans MAC, Beijers R, Riksen-Walraven MJ, de Weerth C. Maternal late pregnancy anxiety and stress is associated with children's health: a longitudinal study. Stress. 2017;20(5):495-504.

88. Huizink AC, Menting B, De Moor MHM, Verhage ML, Kunseler FC, Schuengel C, et al. From prenatal anxiety to parenting stress: a longitudinal study. 2017;20(5):663-72.

89. Waqas A, Elhady M, Surya Dila KA, Kaboub F, Van Trinh L, Nhien CH, et al. Association between maternal depression and risk of infant diarrhea: a systematic review and meta-analysis. Public Health. 2018;159:78-88.

90. O'Connor E, Senger CA, Henninger ML, Coppola E, Gaynes BN. Interventions to Prevent Perinatal Depression: Evidence Report and Systematic Review for the US Preventive Services Task Force. Jama. 2019;321(6):588-601.

91. Melville JL, Reed SD, Russo J, Croicu CA, Ludman E, LaRocco-Cockburn A, et al. Improving care for depression in obstetrics and gynecology: a randomized controlled trial. Obstet Gynecol. 2014;123(6):1237-46. 
92. O'Connor E, Rossom RC, Henninger M, Groom HC, Burda BU. Primary Care Screening for and Treatment of Depression in Pregnant and Postpartum Women: Evidence Report and Systematic Review for the US Preventive Services Task Force. Jama. 2016;315(4):388-406.

93. Mossie TB, Sibhatu AK, Dargie A, Ayele AD. Prevalence of Antenatal Depressive Symptoms and Associated Factors among Pregnant Women in Maichew, North Ethiopia: An Institution Based Study. Ethiopian Journal of Health Sciences. 2017;27(1):59-66.

94. Gerstein ED, Njoroge WF, Paul RA, Smyser CD, Rogers CEJJotAAoC, Psychiatry A. Maternal Depression and Stress in the Neonatal Intensive Care Unit: Associations With Mother- Child Interactions at Age 5 Years. 2019;58(3):350-8. e2.

95. Easter A, Howard LM, Sandall J. Recognition and response to life-threatening situations among women with perinatal mental illness: a qualitative study. BMJ Open. 2019;9(3):e025872.

96. Byatt. N, Carter. D, Deligiannidis. KM, Epperson. CN, Meltzer-Brody. S, Payne. JL, et al. Position Statement on Screening and Treatment of Mood and Anxiety Disorders During Pregnancy and Postpartum. 2018.

97. Corti S, Pileri P, Mazzocco MI, Mando C, Moscatiello AF, Cattaneo D, et al. Neonatal Outcomes in Maternal Depression in Relation to Intrauterine Drug Exposure. Frontiers in pediatrics. 2019;7:309.

98. Curry SJ, Krist AH, Owens DK, Barry MJ, Caughey AB, Davidson KW, et al. Interventions to Prevent Perinatal Depression: US Preventive Services Task Force Recommendation Statement. Jama. 2019;321(6):580-7.

99. Sockol LE. A systematic review of the efficacy of cognitive behavioral therapy for treating and preventing perinatal depression. J Affect Disord. 2015;177:7-21.

100. Petersen I, van Rensburg A, Kigozi F, Semrau M, Hanlon C, Abdulmalik J, et al. Scaling up integrated primary mental health in six low- and middle-income countries: obstacles, synergies and implications for systems reform. BJPsych Open. 2019;5(5):e69.

101. Bitew T, Keynejad R, Honikman S, Sorsdahl K, Myers B, Fekadu A, et al. Stakeholder perspectives on antenatal depression and the potential for psychological intervention in rural Ethiopia: a qualitative study. BMC pregnancy and childbirth. 2020;20(1):371-.

102. Reilly N, Harris S, Loxton D, Chojenta C, Forder P, Milgrom J, et al. Referral for management of emotional health issues during the perinatal period: does mental health assessment make a difference? Birth. 2013;40(4):297-306.

103. Reilly N, Harris S, Loxton D, Chojenta C, Forder P, Austin MP. The impact of routine assessment of past or current mental health on help-seeking in the perinatal period. Women and birth : journal of the Australian College of Midwives. 2014;27(4):e20-7.

104. Reay R, Matthey S, Ellwood D, Scott M. Long-term outcomes of participants in a perinatal depression early detection program. J Affect Disord. 2011;129(1-3):94-103.

105. El-Den S, O'Reilly CL, Chen TF. A systematic review on the acceptability of perinatal depression screening. J Affect Disord. 2015;188:284-303. 
106. Bayrampour H, McNeil DA, Benzies K, Salmon C, Gelb K, Tough S. A qualitative inquiry on pregnant women's preferences for mental health screening. BMC pregnancy and childbirth. 2017;17(1):339.

107. Austin M, Highet N, Excellence EWGJMCoP. Mental health care in the perinatal period: Australian clinical practice guideline. 2017.

108. Marley JV, Kotz J, Engelke C, Williams M, Stephen D, Coutinho S, et al. Validity and Acceptability of Kimberley Mum's Mood Scale to Screen for Perinatal Anxiety and Depression in Remote Aboriginal Health Care Settings. PLOS ONE. 2017;12(1):e0168969.

109. Tsai AC, Scott JA, Hung KJ, Zhu JQ, Matthews LT, Psaros C, et al. Reliability and validity of instruments for assessing perinatal depression in African settings: Systematic review and metaanalysis. PLoS ONE. 2013;8(12). 